\title{
ARTICLE
}

\section{Monitoring and conservation of the Critically Endangered Alaotran gentle lemur Hapalemur alaotrensis}

\author{
Gurutzeta Guillera-Arroita,',l, José J. Lahoz-Monfort',", \\ E. J. Milner-Gulland', Richard P. Young ${ }^{11, \mathrm{IV}}$ and \\ Emily Nicholson'
}

\author{
Correspondence: \\ Gurutzeta Guillera-Arroita \\ National Centre for Statistical Ecology, School of Mathematics, \\ Statistics and Actuarial Science, University of Kent, Canterbury, \\ Kent, CT2 7NZ, UK \\ E-mail: gg63@kent.ac.uk
}

\begin{abstract}
The Alaotran gentle lemur Hapalemur alaotrensis is a Critically Endangered lemur, which exclusively inhabits the marshes around Lac Alaotra in northeast Madagascar. In the past decades the population of $H$. alaotrensis has experienced a dramatic decline due to poaching, habitat destruction and degradation. Surveys have been carried out periodically to follow the status of the population. Here we present the results of a survey carried out between May and June 2008 in the southwestern part of the marshes around Alaotra and discuss the key findings derived from the analysis of the data collected. Our study indicates that the probability of detecting the species in an area where it is present is very low and depends on factors that vary in space and time. These results stress the need to account for imperfect detection when monitoring this species, an issue especially relevant when reporting population trends. Our analyses also show that habitat fragmentation is a key determinant of habitat suitability for $\mathrm{H}$. alaotrensis, with fragmented areas of marsh showing low suitability. Finally, our observations and analysis suggest that the protection provided by the local community to $\mathrm{H}$. alaotrensis in Andreba is contributing to the conservation of this Critically Endangered species. This highlights the need to continue working on engaging the local communities in the conservation of the marshes at Lac Alaotra as a critical element to secure the future of $H$. alaotrensis.
\end{abstract}

\section{RÉSUMÉ}

L'Hapalémur du lac Alaotra Hapalemur alaotrensis est un lémurien en danger critique d'extinction qui habite exclusivement dans les marais autour du lac Alaotra au nord-est de Madagascar. La population de $H$. alaotrensis a connu un déclin dramatique au cours des dernières décennies à cause du braconnage et de la destruction et la dégradation de son habitat.

Des suivis écologiques ont été réalisés périodiquement pour appréhender la situation de la population. Nous présentons ici les résultats d'un suivi écologique effectué entre mai et juin 2008 dans la partie sud-ouest du marais de l'Alaotra et nous examinons les principales conclusions dérivées de
I'analyse des données obtenues. À partir de données de détection / non-détection, nous avons procédé avec une technique de modélisation de l'occupation de I'habitat qui tient compte explicitement de la probabilité de détecter l'espèce, en permettant d'introduire des co-variables pour expliquer l'occupation et la détectabilité. Notre étude montre que dans les zones où I'espèce est présente, la probabilité de la détecter est très basse et dépend de facteurs qui varient dans l'espace et le temps. Ces résultats mettent en exergue le besoin de considérer que la détection de cette espèce n'est pas parfaite, aspect particulièrement important dans l'étude des tendances de populations. Nous avons également utilisé les coordonnées des localités où les lémuriens ont été observés pendant le suivi ainsi que des variables prédictives obtenues à partir d'images du satellite Landsat7 pour la zone de l'Alaotra afin de modéliser la qualité de I'habitat pour $H$. alaotrensis avec le logiciel Maxent et produire une carte du marais de l'Alaotra qui peut servir d'outil à la gestion du marais dans le cadre de la protection de cette espèce. Notre analyse montre également que la fragmentation de la végétation du marais est un facteur déterminant de la qualité de l'habitat, les zones les plus fragmentées étant les moins favorables. Finalement, nos observations et nos analyses suggèrent que la protection fournie par la communauté locale d'Andreba-Gare contribue à la protection de cette espèce en danger critique d'extinction. Cet aspect souligne l'importance de poursuivre le travail de sensibilisation des communautés locales dans la protection du marais du lac Alaotra comme élément critique pour assurer la survie de $H$. alaotrensis.

KEYWORDS: bandro, habitat suitability, habitat fragmentation, imperfect detection, Maxent.

MOTS CLEFS : bandro, modélisation de I'habitat, fragmentation, détection imparfaite, Maxent.

\section{INTRODUCTION}

The Alaotran gentle lemur Hapalemur alaotrensis (Rumpler 1975), initially regarded as a subspecies of the lesser gentle lemur Hapalemur griseus but currently considered a 
separate species (Groves 2005), only occurs in the marshes around Lac Alaotra, in the Alaotra-Mangoro Region, northeast Madagascar. With around 20,000 ha of open water area, Lac Alaotra is Madagascar's largest lake and constitutes one of the main inland fisheries in the country. The lake is surrounded by a vast wetland consisting of marshes and rice fields and is considered an important biodiversity area (Pidgeon 1996). Due to its biological value, the whole Alaotra watershed was designated a wetland of international importance under the Ramsar Convention in 2003 (Ramanampamonjy et al. 2003). Cyperus madagascariensis and Phragmites communis dominate the vegetation in the marsh. In the past decades large areas of marsh have disappeared as a result of conversion into rice paddies. The Alaotran basin produces a large proportion of the national rice harvest (Pidgeon 1996) and is popularly known as 'the granary of Madagascar'. While estimates of original extent of natural marsh range from 60,000 to 80,000 ha (Mutschler and Feistner 1995), at present the remaining marsh surface is less than half of that (Ramanampamonjy et al. 2003, Bakoariniaina et al. 2006) and suffers from degradation through uncontrolled burning (Copsey et al. 2009), siltation due to erosion in the surrounding hills and the spread of invasive plants. The severe loss and degradation of the marsh, together with pressures from hunting, fishing and exotic species, is threatening the survival of various local species. In 2007 a Nouvelle Aire Protégée NAP (IUCN category VI protected area) was declared to officially protect the Alaotran marshes. The NAP set out a number of management zones for the marsh and open water, including no-fishing zones, areas for strict biodiversity conservation, and areas of regulated fishing and reed extraction, although no formal management authority exists yet to ensure compliance.

Hapalemur alaotrensis is the only primate known to exclusively inhabit marsh vegetation. It occurs in two subpopulations: A very small one in the northern part of Lac Alaotra around the Belempona Peninsula and a larger one in the southwestern marshlands. $H$. alaotrensis is highly territorial, with groups actively defending their home ranges against incursions by other groups (Nievergelt et al. 1998). Social groups generally range from two to nine individuals (mean $=3.3$, Mutschler and Feistner 1995; mean $=4.3$, Nievergelt et al. 2002) and occupy home ranges of 0.6-8 ha (Mutschler and Tan 2003) with a mean home range size of around two hectares (Mutschler et al. 1994). This species can be active throughout the day and night, with peaks of activity at the beginning and end of the daylight cycle (Mutschler et al. 1998). H. alaotrensis is exclusively folivorous and feeds on only a few species, mainly Cyperus madagascariensis, Phragmites communis and Echinochloa crusgalli (Mutschler et al. 1998). It may require tall strong vegetation for moving across the marsh and it has been observed in previous studies mostly in mature C. madagascariensis and P. communis stands with a diversity of undergrowth species, typical of areas where marsh fires have not occurred in several years (Ralainasolo 2004a). Man-made channels often mark territory boundaries; although $\mathrm{H}$. alaotrensis can swim, they rarely do and seem to avoid open water (Mutschler et al. 1994). We can therefore hypothesize that the habitat fragmentation that can result from uncontrolled fires in the marsh would have a strong negative impact on $\mathrm{H}$. alaotrensis, considering its locomotion style based on leaping and walking on bent stems along contiguous vegetation, but the influence of habitat fragmentation or plant species diversity on habitat suitability has not yet been investigated systematically.

Hapalemur alaotrensis is classified as Critically Endangered by the IUCN (IUCN 2009). Its survival is threatened by the destruction and degradation of its marsh habitat as well as poaching. These factors appear to have caused a dramatic decline in the population in recent decades (Ralainasolo et al. 2006). Despite laws protecting lemurs in Madagascar, illegal hunting has been identified as a key threat for this species (Mutschler et al. 2001). Some poaching still occurs, although it is believed that awareness and educational campaigns carried out around the lake have reduced its intensity (Ralainasolo 2004b; B. J. Rasolonjatovo, pers. comm.).

Since 1990, Durrell Wildife Conservation Trust has been engaged in the conservation of Hapalemur alaotrensis and has conducted surveys to track the status of the population. Prior to this, very little fieldwork had been conducted on this species (Petter and Peyrieras 1970, Pollock 1986). In 1994 a six-month field study assessed its distribution, population and conservation status (Mutschler and Feistner 1995). Abundance was estimated using a method based on relating the number of 'groups encountered per hour of search' in different areas of the marsh to the group encounter rate from an area where density had been measured based on marked and radio-collared individuals, that is, calibrating a population index (Sutherland 2006: 165) but using a single calibration point and assuming a linear relationship and zero intercept. In 1999, a two-month survey was carried out following the same methods to estimate group encounter rates and compare them with the 1994 figures (Mutschler et al. 2001). In 2001 and 2002, surveys based on the same field protocols collected data to estimate abundance based on encounter rates of individuals (Ralainasolo 2004b).

Monitoring Hapalemur alaotrensis is not easy. The species is difficult to detect since visibility is restricted to the first few metres of vegetation and access to the marsh is limited to canals cut by fishermen. Given the characteristics of the Alaotra system, it is reasonable to expect some degree of variation in the conditions that determine the likelihood of detecting the species in areas it occupies (e.g., changes in water level may cause differences in detectability). The previously used monitoring method based on encounter rates did not account for potential spatio-temporal variation in detection probability, which may confound true changes in population: It is not possible to distinguish an increase in population from an increase in detection probability. Another important limitation of the previous monitoring methodology is that the calibration of the population index (i.e., encounter rate) using only one calibration point does not allow for the quantification of the uncertainty associated with the estimate. Occupancy, defined as the probability of a site being occupied by the species, is often considered a useful variable for the monitoring of rare and elusive species as it can provide sufficient information about the status of the population and detection / non-detection data are relatively easy to collect (Mackenzie et al. 2006). A framework for modelling occupancy while accounting for imperfect detection is thus an attractive alternative to current methods for monitoring $H$. alaotrensis, as it helps discriminate changes in occupancy from changes in detectability, and provides a quantification of the uncertainty associated with the estimates. 
In this paper we present the key findings of the analysis of data collected during a survey carried out between May and June 2008 in the southwestern part of the Lac Alaotra marshes. We analyzed these data to (1) calculate encounter rates of Hapalemur alaotrensis; (2) estimate the probability of site occupancy of this lemur and evaluate how it is affected by relevant covariates; (3) explore how different factors affect the probability of detecting $\mathrm{H}$. alaotrensis in areas occupied by the species; (4) investigate daily activity patterns to identify optimal times for monitoring and (5) build a model of habitat suitability based on habitat characteristics derived from satellite imagery. The part of the study addressing (2) and (3) was originally published in Guillera-Arroita et al. (2010), and (5) in Lahoz-Monfort et al. (2010). Here we discuss all the results in the context of previous studies and examine their implication for the monitoring and conservation of this Critically Endangered species.

\section{METHODS}

DATA SAMPLING. We conducted surveys through the marsh during the dry season between 21 April and 4 June 2008, concentrating on the area between the villages of Anororo, Andreba Gare, Andilana Atsimo and Ambodivoara, where the southern and largest population of Hapalemur alaotrensis occurs. We accessed the marsh from these villages and carried out transects within their 'village management zones' (areas of marsh regulated by the community for fishing and reed harvesting). The survey was conducted by canoe at a regular speed (ca. 1-3 km/h) along existing channels used by fishermen and bordering lake vegetation (Figure 1). We made repeat visits to each transect (from three to 12 , six on average) to obtain the information needed to account for the 'imperfect detection' of the species. Two teams carried out surveys twice a day, in the early morning (0530-0900h) and in the afternoon (1500-1800h), when the lemurs are more active. Each team consisted of one researcher, one local expert (Alaotra fishermen experienced in assisting in the scientific work of Durrell Wildlife Conservation Trust) and one local villager as additional paddler. Teams rotated in surveying transects to avoid heterogeneity in the

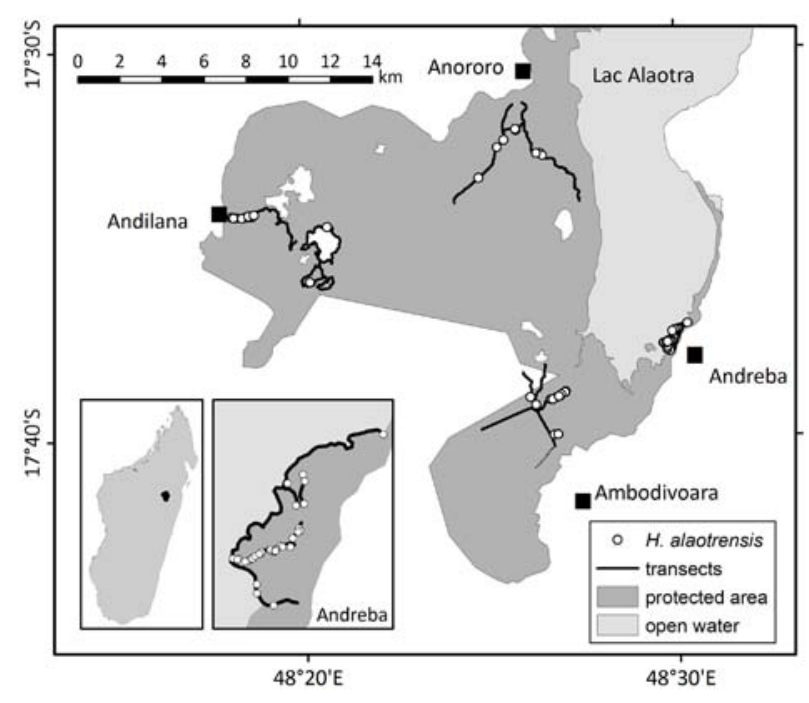

FIGURE 1. Survey transects and position of Hapalemur alaotrensis encounters. The Nouvelle Aire Protégée covers most of the remaining Alaotra marsh. The four villages used as bases for the study are also shown. Detail on the surveyed area in Andreba is shown in an inset. A section of the Sahabe River (dotted line) was also visited once but was excluded from our surveys as most of the marsh area had been recently converted into rice paddies. data due to observer effects. Transects were surveyed in a different order when possible to avoid visiting the same sites at the same time of day.

We collected data on direct observations of Hapalemur alaotrensis, including the time of day, the number of individuals spotted in each group and their activity. The location of each sighting was recorded with a GPS. We recorded qualitative information on habitat characteristics at $30 \mathrm{~m}$ intervals along transects, including the main structural species, species composition and an overall impression of habitat density and patchiness. The average number of canoes encountered per hour of survey was recorded for each transect as an indication of traffic at the time of survey.

DATA ANALYSIS. The data were used to perform

an exploratory analysis of activity patterns. We calculated the percentage of group encounters in which the lemurs were engaged in different activities categorized as feeding, moving amongst the vegetation, scent marking or defending their territory, grooming and resting. We examined how group encounter rates change with the time of the day by comparing the number of sightings with the total amount of time spent in the marsh, broken into 20 -minute time intervals. For this we also considered the periods of time spent in the marsh accessing and returning along transects, even if outside the established surveying times. For each of the four village management zones surveyed (Andreba, Anororo, Ambodivoara and Andilana) we calculated group encounter rates by dividing the total number of group encounters by the total time spent actually surveying. These figures were then compared to those from previous studies.

The detection data were analyzed using an occupancy modelling framework (Mackenzie et al. 2006) that allows the estimation of the probability of site occupancy while accounting for imperfect detection. The method consists on a sampling protocol that involves repeated surveys at a number of sampling sites. This repetition in surveys provides information that allows the model to account for species imperfect detection by explicitly considering that the apparent absence of the species at a site during a survey may reflect two possible situations: 1) the species was truly absent at the site or 2) the species was present at the site but was missed in the survey (i.e., false absence). We used maximum-likelihood as a method for inference and defined as sampling sites sections of transect of $150 \mathrm{~m}$, roughly the size of an average home range. We incorporated into the model four site characteristics thought to be relevant (canoe traffic, habitat category, lake edge vs. channel, nearest village) to explore their effect on the probability of occupancy and detection. Recorded canoe traffic was used to identify infrequently used transects ( $<1$ canoe per hour of fieldwork) from those with moderate or high traffic (>1 canoe per hour of fieldwork). Habitat category was assigned to each sampling site based on the habitat information collected in the field, following the classification used by Mutschler et al. (2001), with an additional class for 'patches of floating invasive plants, large patches of grass or extremely low density stands of Cyperus madagascariensis'. Habitat category was used as a proxy of habitat characteristics in the area, but given that data only captured the characteristics of the first metres of vegetation it may not always have provided an accurate description of the habitat beyond. For more details on covariates, model fitting and model selection see Guillera-Arroita et al. (2010). 
We used freely available Landsat7 satellite images from March 2007, with a pixel resolution of 30m, to create a model of habitat suitability for Hapalemur alaotrensis with the free software Maxent v3.2.1 (Phillips et al. 2006), which applies the maximum entropy modelling framework (Jaynes 1957) to habitat suitability modelling. It attempts to find the least constrained (maximum entropy) distribution that agrees with all the observed data (the value of the covariates at locations where the species was detected). The method only requires presence records although randomly selected background locations are used to characterise the features. It has been shown to perform well compared to other habitat modelling techniques even with only a few samples (Elith et al. 2006). Model validation was based on AUC, the Area Under the ROC (Receiver Operating Characteristic) Curve, which provides a threshold-independent evaluation statistic of model performance. An AUC of 0.5 indicates a prediction no better than random while the closer the values are to 1 the better the model is able to predict. In order to obtain ROC curves and AUC figures, $H$. alaotrensis presence points were randomly divided into calibration (training) and evaluation (test) sets, with $25 \%$ of the samples for evaluation. The modelling was performed 1,000 times with different random partitions of evaluation and calibration sets, and evaluation AUC figures were averaged to avoid them being influenced by particular lemur sightings. All predictor variables were derived from the Landsat7 images and included vegetation indices (related to plant productivity) and image textures (related to habitat fragmentation). Image textures were calculated at different scales, based on a moving window with sizes ranging from three to 11 pixels, which allowed us to study the effect of habitat fragmentation on habitat suitability at different scales potentially relevant for $H$. alaotrensis, whose average territory size (i.e., two hectares) would correspond approximately to $5 \times 5$ pixels and maximum (i.e., eight hectares) to around $9 \times 9$ pixels. We note that our modelling approach does not assume preconceived habitat categories based on previous knowledge, as this would introduce circularity in our analysis. For further details on the remotely sensed covariates, variable selection procedure and modelling methods, see Lahoz-Monfort et al. (2010).

\section{RESULTS}

In 120 hours of survey in the marsh, 71 encounters of Hapalemur alaotrensis groups were recorded (Figure 1). This number includes repeated encounters in different surveys of some groups. H. alaotrensis encounters were relatively frequent in some areas while no groups were found in others, which suggests that the presence of the species or the probability of detection, or both, depend on characteristics of the sites surveyed. The number of individuals recorded in each group encounter ranged from one to eight (average $=2.9$; Figure 2) . These group sizes are somewhat lower than those reported in the literature, which could indicate that some individuals within the groups remained undetected during our surveys.

Encounter rates were similar during the morning and afternoon surveys (Figure 3). Very few groups were encountered after 0830h despite considerable survey effort. Observations before $1600 \mathrm{~h}$ were also rare. Groups observed were engaged in different activities, which we recorded for 55 group encounters: Feeding (45.5\%), moving through the vegetation $(21.8 \%)$, marking or defending their territories against other neigh-

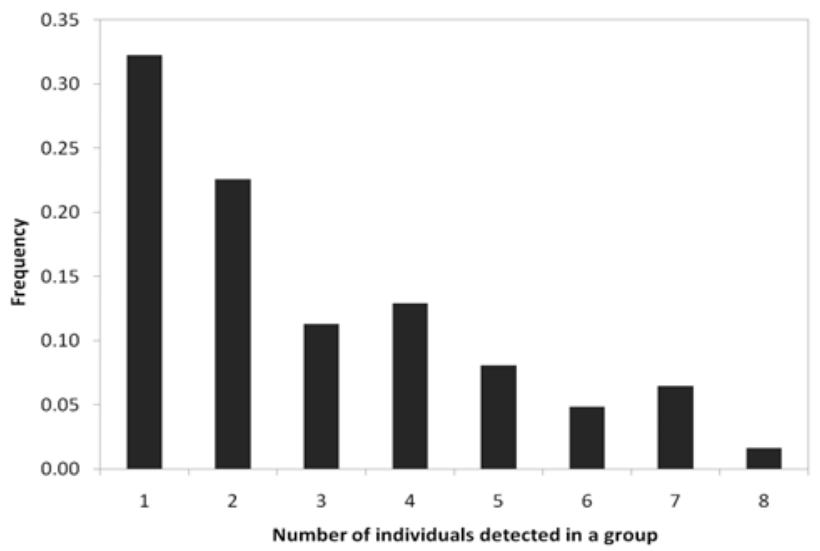

FIGURE 2. Frequency of the number of Hapalemur alaotrensis individuals recorded in each group encounter. These figures represent a lower limit for group size as some individuals might have been missed by the observers.

bouring groups (14.5\%). A few groups were observed resting amongst the vegetation (12.7\%) and grooming (5.4\%). $57.8 \%$ of the groups were seen on Cyperus madagascariensis, $29.6 \%$ on Phragmites communis and the remaining $12.7 \%$ on mixed vegetation (including grass patches, mostly in Andreba).

Group encounter rates (Table 1) varied substantially between village management zones. Encounters were frequent in the area of marsh surveyed in Andreba while the lowest encounter rates were found around Anororo. Compared to the figures from previous studies, encounter rates were relatively high. The figure from Andreba (1.59 group encounters per hour) was twice the largest rate previously recorded (0.72 in 1994) and substantially higher compared to those from other villages. Note that in Andreba we only surveyed the northern part of the marsh while other studies (e.g., Mutschler et al. 2001) may have surveyed the southern part of the marsh as well, where encounter rates tend to be lower. In Ambodivoara the encounter rate was also the largest recorded (0.48), but similar to the second largest (0.40 in 1999). The encounter rate in Andilana (0.40) was slightly lower than the highest recorded (0.47 in 1994), but higher than later figures. In Anororo the figure was roughly half the maximum encounter rate recorded (0.28 vs. 0.51) but several times higher than in more recent surveys.

The results of jointly modelling the probability occupancy and detection (Guillera-Arroita et al. 2010) indicate that these two quantities are not constant but depend on site characteristics (Table 2). Our models estimated that the average probability of site occupancy for the area surveyed was 0.208 (SE $=0.043$ )

TABLE 1. Encounter rates of $H$. alaotrensis groups during the 2008 survey compared to figures from previous surveys. ER: Group encounter rate (groups per hour). Note that the areas surveyed in each locality may vary among different years. 1) Mutschler and Feistner (1995), 2) Mutschler et al. (2001), 3) Ralainasolo (2004b).

\begin{tabular}{|c|c|c|c|c|c|c|c|}
\hline & \multicolumn{3}{|c|}{2008} & \multirow{2}{*}{$\begin{array}{c}1994 \\
(1) \\
E R\end{array}$} & \multirow{2}{*}{$\begin{array}{c}1999 \\
(2) \\
E R\end{array}$} & \multirow{2}{*}{$\begin{array}{c}2001 \\
(3) \\
E R\end{array}$} & \multirow{2}{*}{$\begin{array}{c}2002 \\
(3) \\
E R\end{array}$} \\
\hline Locality & $\begin{array}{c}\text { Group } \\
\text { encounters }\end{array}$ & $\begin{array}{c}\text { Survey } \\
\text { time } \\
\text { (min) }\end{array}$ & ER & & & & \\
\hline Andreba & 32 & 1210 & 1.59 & 0.72 & 0.36 & 0.56 & 0.67 \\
\hline Ambodivoara & 15 & 1878 & 0.48 & --- & 0.40 & 0.07 & 0.27 \\
\hline Andilana & 15 & 2226 & 0.4 & 0.47 & 0.07 & 0.02 & 0.15 \\
\hline Anororo & 9 & 1922 & 0.28 & 0.51 & 0.25 & 0.08 & 0.07 \\
\hline
\end{tabular}




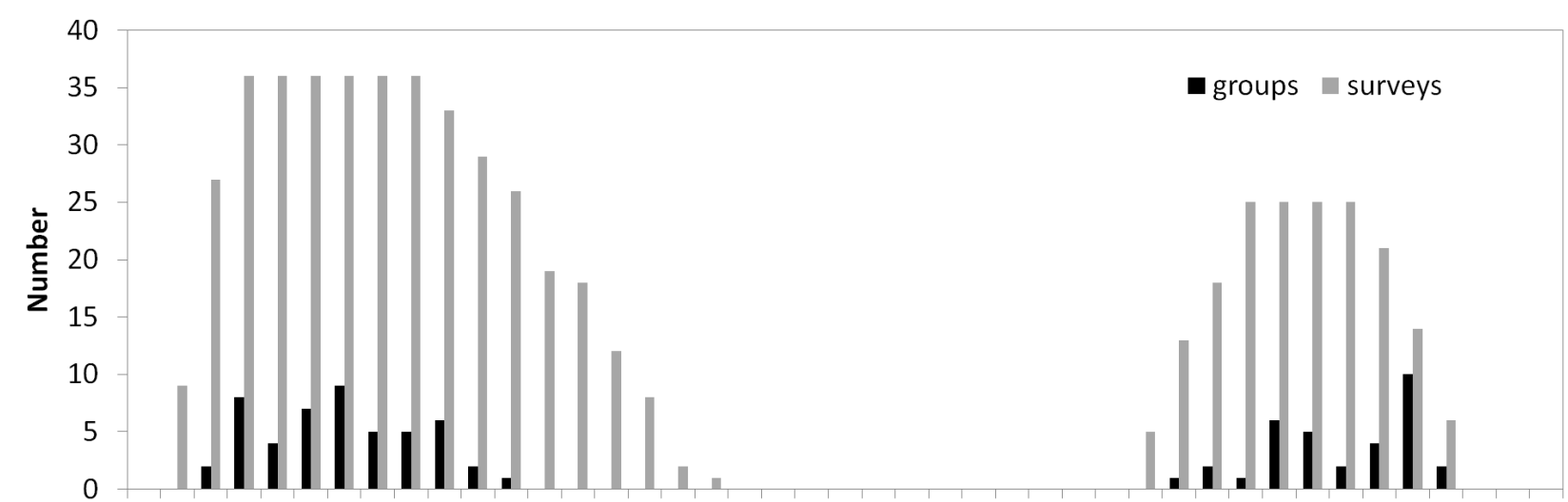

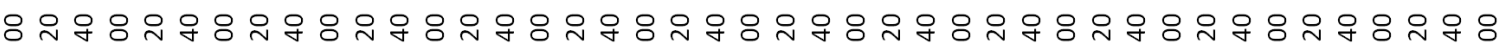 仿 Time}

FIGURE 3. Number of visits to the marsh and number of group encounters of Hapalemur alaotrensis, in 20-minute time intervals.

and suggest that occupancy depends on the characteristics of the habitat at the site, which village manages the area and whether the site is by a lake or a channel. Our analysis showed that, after controlling for other factors such as habitat conditions, the probability of a site being occupied by Hapalemur alaotrensis was higher in two of the village management zones surveyed (Andreba and Andilana) compared to the other two (Ambodivoara and Anororo). The models indicated that detection probability is very low for this species and is related to the amount of canoe traffic occurring at the site. According to our estimates, the probability of detecting $\mathrm{H}$. alaotrensis at a site which is used by the species was around $18 \%$ for transects with low traffic (less than one pirogue encountered per hour of fieldwork), and as low as $5 \%$ for transects supporting higher levels of traffic (more than one pirogue encountered per hour).

The results of our habitat modelling (with an evaluation AUC of 0.861 ) suggest that both vegetation productivity and habitat fragmentation are important determinants of habitat suitability for Hapalemur alaotrensis. High values of the NDVI (Normalized Difference Vegetation Index), an index of vegetation greenness, increased suitability. High NDVI values are typical of healthy marsh. On the other hand, fragmentation of the marsh reduced suitability, both due to the reduction in the amount of healthy marsh in an area and the patchiness of the fragmented marsh. The spatial scale at which habitat fragmentation was taken into account in the model appeared important, with highest predictive power achieved for different predictors at different scales, from Landsat7 pixel size $(30 \times 30 \mathrm{~m})$ up to the average territory size of $H$. alaotrensis. The map of habitat suitability produced with Maxent can be seen in Figure 4. A detailed description of

TABLE 2. Average site occupancy and detectability estimates for $H$. alaotrensis in each of the four areas surveyed. Estimates were obtained averaging models that had similar support (Guillera-Arroita et al. 2010). Standard errors are shown in brackets.

\begin{tabular}{lcl}
\hline Locality & Occupancy & Detectability \\
\hline Andreba & $0.701(0.192)$ & $0.084(0.032)$ \\
\hline Ambodivoara & $0.197(0.082)$ & $0.061(0.063)$ \\
\hline Andilana & $0.264(0.059)$ & $0.060(0.027)$ \\
\hline Anororo & $0.095(0.051)$ & $0.051(0.016)$ \\
\hline Overall & $0.208(0.043)$ & $0.063(0.015)$ \\
\hline
\end{tabular}

the results in relation to the predictor variables can be found in Lahoz-Monfort et al. (2010).

\section{DISCUSSION}

DETECTABILITY.The results of the Guillera-Arroita et al.

(2010) occupancy model showed that the probability of detecting Hapalemur alaotrensis in areas used by the species is very low and varies with factors that change in space and time. This highlights the need to account for imperfect detection when monitoring the species, both in the design phase of the study and the subsequent analysis of the data. As expected, our data showed that the probability of detecting the species is highly dependent on the time of the day. Monitoring of this species should therefore be carried out during the active periods to maximize the probability of detection and thus optimize the use of monitoring resources. Our analysis identified the amount of canoe traffic as another important factor affecting the probability of detection. We suspect that the effects of water level on visibility may also be relevant, although we could not explore it due to the timeframe of our study. Mutschler et al. (2001) noted a potential decrease in visibility affecting their 1999 survey, as a result of an unusual drought during the first months of the year.

changes in detection probability can confound estimates of change in populations, making it impossible to interpret observed trends in sightings of lemurs as real population trends. Therefore it is especially important to account for this issue when comparing results from different areas or years, or different studies. A comparison of our data with that of previous surveys (Mutschler and Feistner 1995, Mutschler et al. 2001, Ralainasolo 2004b) using the usual group encounter rate method would suggest an increase in Hapalemur alaotrensis population. However, this could also reflect differences in detection probability, for instance due to better visibility conditions or different levels of canoe traffic in the areas selected for survey. Although looking at the encounter rates can provide some insights about the population, we stress the need to use a method of analysis that accounts explicitly for detection probability, like the occupancy framework utilized in our study or alternatively distance sampling (Buckland et al. 2001). The occupancy framework also allows us to incorporate factors that affect both occupancy 


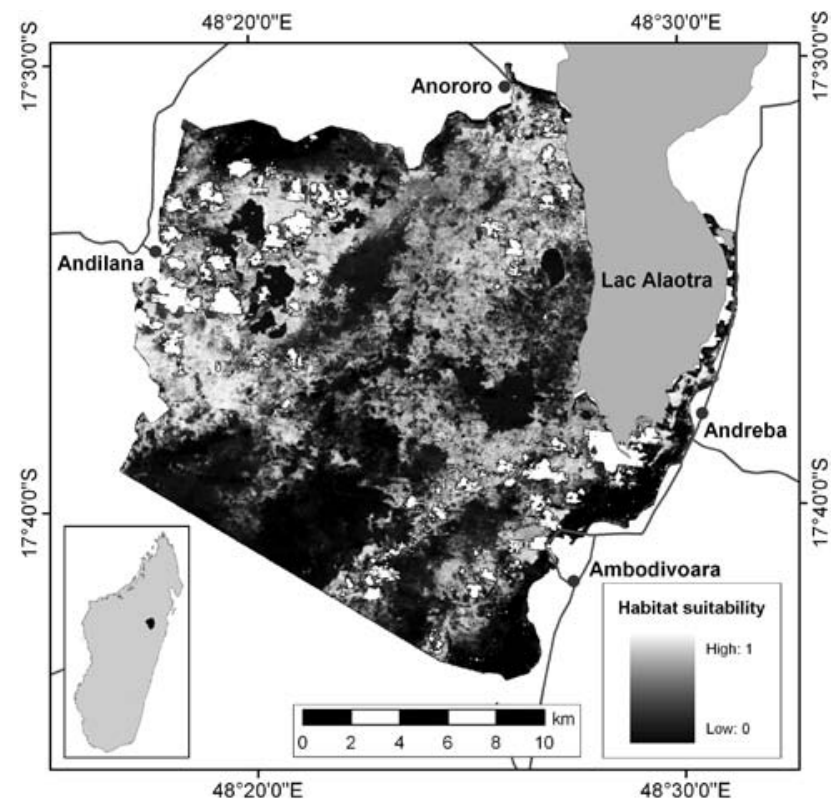

FIGURE 4. Habitat suitability map obtained with Maxent for Hapalemur alaotrensis as a continuous index (logistic output). Empty patches correspond to clouds in the Landsat image. This map is reproduced from Lahoz-Monfort et al. (2010).

and detection probability into our models and enables us to generate measures of the reliability of our estimates (i.e., confidence intervals) which is important when making conclusions about trends.

IMPACT OF HABITAT FRAGMENTATION ON HABITAT

SUITABILITY. The Lahoz-Monfort et al. (2010) habitat model based on satellite images provided estimates of habitat suitability beyond the bounds of our field surveys along existing channels and lake edges, which is particularly relevant given the extent of the Lac Alaotra marshes that is impenetrable. Both vegetation productivity and low fragmentation contributed to habitat suitability. This may be as expected, but it is noteworthy that our method did not impose preconceived ideas about what constitutes 'suitable' habitat, based upon our ecological understanding or previous experience. This means that the results of the study are not circular (i.e., it would not be surprising to see lemurs in habitat categories that have been defined as suitable a priori based on where you expect to see them). Instead, the method tested whether objective measures of fragmentation and greenness in the satellite image did in fact characterise areas of lemur presence. The results reinforce the understanding of the ecology of the species built up from previous studies, and support the hypothesis that habitat fragmentation has a strong influence on the suitability of the marsh for Hapalemur alaotrensis. The relationship estimated by the model for the fragmentation covariates calculated for different sizes suggested that habitat fragmentation affects $H$. alaotrensis at different scales. It suggests that the movement of the lemurs at a small scale is hindered, and the amount of healthy marsh (and thus food and shelter) at a larger scale is reduced within a potential territory. The dynamics of marsh burning are not simple but there is evidence that burnt areas are likely to develop into low quality fragmented habitat (Andrianandrasana 2009). During our survey we did not find a single individual of $H$. alaotrensis in areas burnt within the last year. This highlights the importance for the conservation of $\mathrm{H}$. alaot- rensis of reducing the amount of large uncontrolled marsh fires and allowing the natural regeneration of the marsh.

THE EFFECTIVENESS OF COMMUNITY INVOLVEMENT

IN PROTECTING HAPALEMUR ALAOTRENSIS. Our results showed that the probability of an area being occupied by Hapalemur alaotrensis varies between village management zones, which could reflect different levels of poaching. Although $H$. alaotrensis is protected and its hunting is illegal, some level of poaching remains. During the time of our study there were reports of poachers being caught and some local villagers acknowledged in informal conversations that hunting still continues in some areas. Our analysis revealed that the probability of occupancy was highest in the marsh surveyed in Andreba, where recorded group sizes also tended to be larger. The habitat in this area was very good for $\mathrm{H}$. alaotrensis, as shown by our habitat suitability model. Although not studied quantitatively, our field observations showed marked differences in behaviour between individuals in this area compared to others. Lemurs were more 'docile' and would remain for a longer time close to us. Previous field studies also recorded higher encounter rates in this area compared to other villages. Andreba has been the focus of ecological studies on $\mathrm{H}$. alaotrensis for years, which, together with the environmental awareness projects carried out around the lake (Andrianandrasana et al. 2005, Maminirina et al. 2006), have raised the awareness of the local community of the importance of the conservation of $\mathrm{H}$. alaotrensis. A community park (Parc villageois $d^{\prime}$ Andreba) was created to regulate the access to this part of the marsh and recently a sustainable nature tourism project was set up by the Malagasy NGO Madagascar Wildlife Conservation to bring more incentives for the community to protect the species. Our observations and analysis indicate that the involvement of the local community in the protection of $H$. alaotrensis in Andreba is contributing to the conservation of this Critically Endangered species. This highlights the need to continue working in the engagement of local communities around the lake as part of the long-term conservation strategy for the marshes of Lac Alaotra.

\section{CONCLUSIONS}

Our study showed that Hapalemur alaotrensis is affected by the fragmentation of its habitat and the quality of the vegetation. This emphasizes the need to avoid large uncontrolled destruction of the marsh (e.g., due to fires) and to allow its natural regeneration. Our data and observations suggested that the engagement of the local community is an effective conservation measure and that it is therefore important to continue working in this direction. By tracking H. alaotrensis population changes, monitoring can inform decisions regarding its conservation. For monitoring to be meaningful, it is critical to account for the imperfect detection of this species, which we have shown can be done using a relatively simple data collection protocol. Involving the local community in the monitoring of the species may provide an opportunity for obtaining larger data sets while contributing to their engagement in the conservation of the Alaotran marshes.

\section{ACKNOWLEDGEMENTS}

We would like to thank the Ministry of Environment, Water and Forests of Madagascar for granting the research permit to conduct this study; the Leverhulme Trust and a Royal Society 
Wolfson Research Merit award to EJMG for financial support; R. Lewis, J. Ratsimbazafy, H. Andrianandrasana and other Durrell Wildlife Conservation Trust personnel in Madagascar, especially B. J. Rasolonjatovo in Ambatondrazaka; and our expert local guides, R. Rasolonjatovo and A. Rakotonierana, for all their hard work and enthusiasm. We also thank the editor and three anonymous reviewers for their useful comments.

\section{REFERENCES}

Andrianandrasana, H. 2009. Développement des Systèmes de Télédétection en Vue d'améliorer le Suivi de I'Habitat et des Feux de Marais à Lac Alaotra. Diplôme d'Études Approfondies (DEA), Université d'Antananarivo, Antananarivo.

Andrianandrasana, H. T., Randriamahefasoa, J., Durbin, J., Lewis, R. E. and Ratsimbazafy, J. H. 2005. Participatory ecological monitoring of the Alaotra wetlands in Madagascar. Biodiversity and Conservation 14, 11 2757-2774. (doi:10.1007/s10531-005-8413-y)

Bakoariniaina, L. N, Kusky, T. and Raharimahefa, T. 2006. Disappearing Lake Alaotra: Monitoring catastrophic erosion, waterway silting, and land degradation hazards in Madagascar using Landsat imagery. Journal of African Earth Sciences 44, 2: 241-252

Buckland, S. T., Anderson, D. R., Burnham, K. P., Laake, J. L., Borchers, D. L. and Thomas, L. 2001. Introduction to Distance Sampling: Estimating Abundance of Biological Populations. Oxford University Press, Oxford.

Copsey, J. A., Jones, J. P. G., Andrianandrasana, H., Rajaonarison, L. H. and Fa, J. E. 2009. Burning to fish: Local explanations for wetland burning in Lac Alaotra, Madagascar. Oryx 43: 403-406. (doi:10.1017/ s0030605309000520)

Elith, J., Graham, C. H., Anderson, R. P., Dudik, M., Ferrier, S., Guisan, A., Hijmans, R. J., Huettmann, F., Leathwick, J. R., Lehmann, A., Li, J., Lohmann, L. G., Loiselle, B. A., Manion, G., Moritz, C., Nakamura, M., Nakazawa, Y., Overton, J. M., Townsend Peterson, A., Phillips, S. J., Richardson, K., Scachetti-Pereira, R., Schapire, R. E., Soberón, J., Williams, S., Wisz, M. S. and Zimmermann, N. E. 2006. Novel methods improve prediction of species' distributions from occurrence data. Ecography 29, 2: 129-151. (doi:10.1111/j.2006.0906-7590.04596.x)

Groves, C. 2005. Order Primates. In: Mammal Species of the World: A Taxonomic and Geographic Reference (Third edition), D. E. Wilson and D. M. Reader (eds.), pp 111-184. The Johns Hopkins University Press, Baltimore.

Guillera-Arroita, G., Lahoz-Monfort, J. J., Milner-Gulland, E. J., Young, R. P. and Nicholson, E. 2010. Using occupancy as a state variable for monitoring the Critically Endangered Alaotran gentle lemur Hapalemur alaotrensis. Endangered Species Research 11: 157-166. (doi:10.3354/esr00274)

IUCN, The International Union for the Conservation of Nature and Natural Resources 2009. IUCN Red List of threatened species. Version 2009.1. Available at: <www.iucnredlist.org>

Jaynes, E. T. 1957. Information theory and statistical mechanics. II. Physical Review 108, 2: 171-190. (doi:10.1103/PhysRev.108.171)

Lahoz-Monfort, J. J., Guillera-Arroita, G., Milner-Gulland, E. J., Young, R. P. and Nicholson, E. 2010. Satellite imagery as a single source of predictor variables for habitat suitability modelling: How Landsat can inform the conservation of a critically endangered lemur. Journal of Applied Ecology 47, 5: 1094-1102. (doi:10.1111/j.1365-2664.2010.01854.X)

Mackenzie, D. I., Nichols, J. D., Royle, J. A., Pollock, K. H., Bailey, L. L. and Hines, J. E. 2006. Occupancy Estimation and Modeling: Inferring Patterns and Dynamics of Species Occurrence. Elsevier Academic Press, New York, USA.

Maminirina C., Girod, P. and Waeber, P. O. 2006. Comic strips as environmental educative tool for the Alaotra Region. Madagascar Conservation \& Development 1, 1: 11-14.

Mutschler, T. and Feistner, A. T. C. 1995. Conservation status and distribution of the Alaotran gentle lemur Hapalemur griseus alaotrensis. Oryx 29: 267-274. (doi:10.1017/S0030605300021268)

Mutschler, T. and Tan, C. L. 2003. Hapalemur, bamboo or gentle lemurs. In: The Natural History of Madagascar. S. M. Goodman and J. P. Benstead (eds.), pp 1324-1329. The University of Chicago Press, Chicago and London.
Mutschler, T., Nievergelt, C. M. and Feistner, A. T. C. 1994. Biology and Conservation of Hapalemur griseus alaotrensis. Unpubl. Report Durrel Wildlife Conservation Trust, Trinity, Jersey.

Mutschler, T., Feistner, A. T. C. and Nievergelt, C. M. 1998. Preliminary field data on group size, diet and activity in the Alaotran gentle lemur Hapalemur griseus alaotrensis. Folia Primatologica 69, 5: 325-330. (doi:10.1159/000021647)

Mutschler, T., Randrianarisoa, A. J. and Feistner, A. T. C. 2001. Population status of the Alaotran gentle lemur (Hapalemur griseus alaotrensis). Oryx 35, 2: 152-157. (doi:10.1046/j.1365-3008.2001.00167.x)

Nievergelt, C. M., Mutschler, T. and Feistner, A. T. C. 1998. Group encounters and territoriality in wild Alaotran gentle lemurs (Hapalemur griseus alaotrensis). American Journal of Primatology 46, 3: 251-258. (doi:10.1002/(SICl)1098-2345(1998)46:3<251::AID-AJP5>3.0.CO;2-H)

Nievergelt, C. M., Mutschler, T., Feistner, A. T. C and Woodruff, D. S. 2002. Social system of the Alaotran gentle lemur (Hapalemur griseus alaotrensis): Genetic characterization of group composition and mating system. American Journal of Primatology 57, 4: 157-176. (doi: 10.1002/ ajp.10046)

Petter, J.-J. \& Peyrieras, A. 1970. Observation éco-éthologiques sur les lémuriens malgaches du genre Hapalemur. La Terre et La Vie 24: 356-382.

Phillips, S., Anderson, R. P. and Schapire, R. E. 2006. Maximum entropy modeling of species geographic distributions. Ecological Modelling 190, 3-4: 231-259. (doi:10.1016/j.ecolmodel.2005.03.026)

Pidgeon, M. 1996. An Ecological Survey of Lake Alaotra and Selected Wetlands of Central and Eastern Madagascar in Analysing the Demise of Madagascar Pochard Aythya innotata. WWF / Missouri Botanical Garden, Antananarivo.

Pollock, J. 1986. A note on the ecology and behavior of Hapalemur griseus. Primate Conservation 7: 97-100.

Ralainasolo, F. B. 2004a. Effets des actions anthropiques sur la dynamique de la population de Hapalemur griseus alaotrensis (Rumpler, 1975) dans son habitat naturel. Diplome d'Études Approfondies (DEA), Université d'Antananarivo, Antananarivo.

Ralainasolo, F. B. 2004b. Influence des effets anthropiques sur la dynamique de population de Hapalemur griseus alaotrensis ou ,bandro, dans son habitat naturel. Lemur News 9: 32-35

Ralainasolo, F. B., Waeber, P. O., Ratsimbazafy, J., Durbin, J. and Lewis, R. E. 2006. The Alaotra gentle lemur: Population estimation and subsequent implications. Madagascar Conservation \& Development 1, 1: 9-10.

Ramanampamonjy, J. R., Rasoamampionona Raminosoa, N., Andrianandrasana, T. H., Wilmé, L., Durbin, J., Lewis, R., Razafindrajao, F., Razafindramahatra, L., Randriamanampisoa, H., Randriamahefasoa, J. and Rakotoniaina, L. J. 2003. Information Sheet on Ramsar Wetlands: Lake Alaotra Wetlands and Catchment Basin. Available at <http:// ramsar.wetlands.org>.

Sutherland, W. J. 2006. Ecological Census Techniques: A Handbook. (Second edition), Cambridge University Press, Cambridge. 